\title{
Actinomycosis as a Cause of Spinal Cord Compression: a Case Report and Review
}

\author{
P. G. Müller, MD \\ Center for Spinal Cord Injured, Department TH, Rigshospitalet, University of \\ Copenhagen, Denmark.
}

\begin{abstract}
Summary
$A$ case is presented of a 40-year-old man with rapidly progressing symptoms of thoracic medullary compression, initially thought to be caused by metastatic pulmonary malignancy. Further investigations, however, revealed thoracic actinomycosis spreading to the vertebral column and an actinomycotic epidural granuloma was causing medullary compression. After decompression by laminectomy and antibiotic treatment with penicillin there was some neurological improvement. The condition is rare, and some of the diagnostic difficulties are discussed.
\end{abstract}

Key words: Actinomycosis; Spinal cord compression; Paraplegia.

Human actinomycosis is a chronic suppurative infection caused by Actinomyces species. Actinomyces are part of the normal anaerobic flora in the oral cavity.

Human actinomycosis is divided into the following clinocoanatomic forms: cervicofacial, thoracic and abdominal. Spread of actinomycosis occurs either by direct invasion, or, less commonly, by haematogenous metastatic dissemination (Lerner, 1985).

Actinomycosis of the spine is uncommon although well described (Cope, 1951; Ernst et al., 1971; Young, 1960). Association with spinal cord compression as occurred in the present case is very rare (Kannangara et al., 1981; Lane et al., 1979; Shibata et al., 1982).

If treated in time the prognosis for human actinomycosis is good, but the condition can be difficult to diagnose.

\section{Case report}

A 40-year-old man was admitted to hospital on 31 July 1986 for treatment of pubic abscesses and fistulae and investigation of suspected pulmonary malignancy. He had had recurrent cutaneous abscesses on his back, perineum, and scrotum for several years 
and for short periods had been treated with various antibiotics with temporary benefit. In February 1986 respiratory symptoms appeared with breathlessness, cough and hemoptysis, and also loss of weight. From 15 July 1986 the patient also noticed weakness of both legs and back ache. A chest X-ray showed a large area of suspected malignant infiltration in the upper lobe of the lung. On admission to hospital the patient was found to have a low grade fever $\left(37.1^{\circ} \mathrm{C}\right.$ orally); slight leucocytosis $\left(12.7 \times 10^{9} / 1\right)$; he was able to walk with only slight difficulty and there was no sensory disturbance. A pubic abscess and several fistulae in the perineum were found and were treated surgically. There was progressive weakness of the legs and on 7 August the patient could barely walk and complained of diffuse hypaesthesia in the trunk from below the umbilicus including both lower limbs. Myelography revealed a total spinal block from the 2nd to 5th thoracic vertebra.

The neurologist concluded that the diagnosis was metastases from a pulmonary malignancy. Operation was contraindicated because of the recently treated abscess with several fistulae, and the patient was transferred for radiotherapy for 10 days, but with no obvious effect on the paresis. Then bronchoscopy was performed and several biopsies were taken from the upper lobe of the right lung but there was no evidence of malignancy. A CATscan guided biopsy was achieved from the right upper lobe and microscopic examination showed non-specific inflammation with foci of actinomycosis, and from 22 August the patient had intravenous penicillin $20 \times 10^{6}$ IU daily for 6 weeks. On 23 August a laminectomy was performed from $\mathrm{T} 1$ to $\mathrm{T} 5$, revealing a paravertebral abscess, osteomyelitis of the arcus of the vertebrae and actinomycotic epidural granuloma. Microbiological examination showed $A$. meyeri to be the probable Actinomyces species. Post-operatively there was total spastic motor paralysis. Sensory impairment was minimal and bowel and bladder function remained intact.

On 13 October the patient was admitted to the Rehabilitation Hospital. There had been slight motor improvement and sensation was normal. Oral penicillin was continued for 1 year and chest $\mathrm{X}$-rays showed regression of the pulmonary changes. He was discharged home on 16 March 1987 being independent in his wheelchair (incomplete paraplegia with midthoracic motor level, sensation intact (Frankel class C). When seen on 22 December 1987 he was able to walk 2-300 m with forearm-crutches.

\section{Discussion}

Human actinomycosis is caused predominantly by Actinomyces israelii, a slow growing, filamentous, anaerobic, gram-positive bacterium, susceptible to penicillin. Other species, such as $A$. naeslundii, A. viscosus, A. odontolyticus and $A$. meyeri, cause disease less frequently (Lerner, 1985).

The essential clinical feature of actinomycosis is that of a chronic granulomatous infection with indurated subcutaneous swellings which may form external sinuses discharging characteristic 'sulphur granules'. The infection may remain localised and sinus tracts may extend into inner organs. The cervicofacial form of the disease, being the commonest manifestation, may follow any surgical or traumatic injury to the oral mucous membrane and many patients have been found to have neglected dental care. Thoracic infections may involve lungs, pleura, mediastinum, or chest wall and, in the absence of a draining sinus, the correct diagnosis is often delayed for a long period. Infections results usually from oropharyngeal aspiration of contaminated material.

Actinomycosis of the spine is probably always secondary to actinomycosis elsewhere in the patient and is a result of direct invasion from a nearby focus of infection almost invariably in the form of a paravertebral phlegmon (Young 1960). The condition is rare and most cases are diagnosed at autopsy (Cope, 1951; Young, 1960). 
The clinical picture of vertebral actinomycosis is vague but back pain is common, usually of a dull and constant nature and often with periods of exacerbation. Occasionally the pain is of a definite nerve or root type (Young, 1960). Often there is remarkable stiffness of the involved vertebral segments (Ernst et al., 1971).

The general symptoms of low grade irregular fever, malaise, loss of weight, moderate leucocytosis and anaemia usually raises the suspicion of malignancy, whilst the vertebral symptoms are neglected or thought to be of metastatic origin. Some authors (Ernst et al., 1972; Young, 1960) report characteristic changes in radiographs of the involved vertebrae, these including irregular saw toothed bodies with honeycomb-like structure of the central parts. These changes were not present in our patient. Vertebral actinomycosis with spinal cord compression has only been reported in 10 patients, with 5 since the introduction of antibiotic treatment (Cope, 1951; Kannangary et al., 1981; Krumdieck et al., 1970; Lane et al., 1979; Parker, 1923; Shibata et al., 1981). Three of these patients were successfully treated with penicillin without surgery (Cope, 1951; Lane et al., 1979).

Usually spinal cord compression is considered to be caused by epidural abscess formation, and only one author (Shibata et al., 1982) has described actinomycosis epidural granuloma.

Our patient is in many respects similar to those previously reported and reveals some of the difficulties in diagnosing actinomycotic spinal cord compression.

Although 3 out of 5 reported cases have been successfully treated without surgery it seems reasonable to treat actinomycotic spinal cord compression like other forms of epidural abscess or granulomas with spinal cord involvement, by prompt drainage of abscesses and, when bone is involved and/or granumalotous tissue is present, by thorough neural decompression (Baker et al., 1975; Kaufman et al., 1980).

The delay in carrying out proper treatment in our patient might in part be responsible for the considerable degree of persisting paraparesis.

\section{Acknowledgements}

The following Departments have kindly supplied information: F 2 Department of Surgery, Bispebjerg Hospital; and ONB Department of Oncology, M Department of Epidemiology, NK Department of Neurosurgery, Department of Neuropathology, and the Department of Microbiology, Rigshospitalet, Copenhagen.

\section{References}

Baker AS, OJemann RG, Swartz MN, et. al. 1975 Spinal epidural abscess. New England fournal of Medicine 293:463-468.

COPE VZ 1951 Actinomycosis of bone with special reference to infection of the vertebral column. Fournal of Bone and foint Surgery 33B:205-214.

ERnSt J, Ratjen E 1971 Actinomycosis of the spine. Acta Orthopaedica Scandinavica 42:35-44.

HANCOCK DO 1973 A study of 49 patients with acute spinal extradural abscess. Paraplegia 10:285-288.

Kannangary DW, Tanaka T, Thadepalli H 1981 Spinal epidural abscess due to Actinomyces israelii. Neurology 31:202-203.

Kaufmann DM, Kaplan JG, Litman N 1980 Infectious agents in spinal epidural abscesses. Neurology 30:844-849. 
Krumdieck n, Stevenson L 1970 Spinal epidural abscess associated with actinomycosis. Archives of Pathology 30:1223-1226.

LANE T, GoINGS S, FRASER DW, et al. 1979 Disseminated actinomycosis with spinal cord compression: Report of two cases. Neurology 29:890-893.

LERNER PI 1985 Actinomyces and arachnia species. In: Mandell GC, Douglass GR Jr, Bennett SE, (eds) Principles and Practice of Infectious Diseases, 2nd edn. John Wiley and Sons, New York, pp 1427-1433.

PARKER CA 1923 Actinomycosis and blastomycosis of the spine. Fournal of Bone and foint Surgery 5:759-777.

Shibata T, Ito A, Inao S, et al. 1981 Actinomycotic spinal epidural granuloma. Neurologia Medico-Chirurgica 22:167-169.

YouNG WB 1960 Actinomycosis with involvement of the vertebral column: Case report and review of the literature. Clinical Radiology 11:175-182. 